\title{
IoT-based Dairy Supply Chain - An Ontological Approach
}

\author{
Bartosz Jachimczyk $^{1,{ }^{*},}$, Rafal Tkaczyk ${ }^{2}$, Tomasz Piotrowski ${ }^{3}$, Sven Johansson ${ }^{1}$, Wlodek J. Kulesza ${ }^{1}$ \\ ${ }^{1}$ Blekinge Institute of Technology, \\ 37179 Karlskrona, Sweden \\ ${ }^{2} D A C S A$, \\ ul. Kolobrzeska 14, 80-394 Gdansk, Poland \\ ${ }^{3}$ Department of Animal Breeding and Production, Warsaw University of Life Sciences, \\ ul. Ciszewskiego 8, 02-786 Warsaw, Poland \\ bartosz.jachimczyk@bth.se
}

\begin{abstract}
Emerging digital transformation in industry is noticeable among others in Supply Chain Management (SCM). For instance, applying new-generation digitalized technologies in the Dairy Supply Chain (DSC) enables an increase of manufacturing productivity, improves planning and forecasting, and also enhances competitive capabilities according to Industry 4.0 assumptions. It is worth mentioning, that in modern DSC, high visibility of raw materials, components, products, and processes by all contributors on all stages of DSC is crucial. This article focuses on the transparency aspect of the DSC supported by IoT-based technologies enabling interoperability among all DSC participants. The paper addresses the problem of effective integration of heterogeneous data sources, i.e., deployed new technological IoT solutions with traditional SCM systems and a third-party software component. The main objective of this report is to propose the IoT-based DSC model comprising four chain stages: milk production, milk transportation, milk processing, and dairy products distribution. Moreover, the comprehensive DSC domain ontology as a knowledge model is formulated and described. The ontology aims on improvement of the DSC management efficiency by facilitating interoperability within DSC. The applicability of the proposed ontological model is verified using a sustainable-oriented case study, which estimates the environmental footprint at the milk transportation stage of the DSC.
\end{abstract}

Index Terms-Dairy value chain; Knowledge model; Semantic web; Supply chain management; Supply chain modelling; Visibility.

\section{INTRODUCTION}

Today's digital transformation as a paradigm shift is visible among others in Supply Chain Management (SCM), regardless of the kind of goods produced. Such a technological revolution through rapid development of the Internet of Things (IoT) concept and its growing applicability, significantly affects the current SCM. In the context of digital transformation, applied IoT solutions along with AI-based tools and Blockchain technologies lead to the so-called Industry 4.0 era.

Manuscript received 7 September, 2020; accepted 20 December, 2020.

This research was funded by ECSEL Joint Undertaking (JU) under Grant No. 783221
The new-generation digitalized technology applied in Supply Chain (SC) enables the increase of manufacturing productivity, improves planning and forecasting, and also enhances competitive capabilities. After all, in the new way of SCM, the high visibility of raw materials, components, and products along with all Supply Chain participants on all stages of SC is crucial [1]. The main reason for preferable visibility-enabling solutions is an enhancement of effectiveness, reliability, and sustainability of the SC.

According to research study [2], the digital transformation is also expected in Dairy Supply Chain (DSC). The research estimates over $£ 399$ million of potential annual gains from digital transformation in the dairy sector by 2025. In general, the DSC constitutes the flow of all dairy and non-dairy materials and products, along with information and funds between the various stages of production and selling of dairy products. Each DSC step, including feed production for dairy farms, milk production and transportation, milk processing in the dairy processing plant, dairy products distribution, consumption and end of life, is a kind of process. Furthermore, DSC comprises of package manufacturing and supply, and also non-dairy ingredients production and supply. Additionally, it constitutes the connection of all parties, businesses, marketing, and distribution activities, through which the product reaches the customer.

A key management objective of the DSC is to meet customer's needs - providing suitable products by so-called primary activities. However, there is also a complementary management approach, Dairy Value Chain (DVC), which focuses on interrelated supportive activities of cooperating partners aimed to create a competitive advantage, understood as the customer's added value. Currently, the management in DVC aims at activities that maintain and enhance product's value in terms of quality, sustainability, etc. [3]-[5].

Each DSC has its own structure and characteristics, and therefore its visibility enhancement needs to be tailored inter alia for a specific production plant, existing regulations, and market demands. To facilitate this process and to provide a common understanding, visibility-oriented DSC model 
needs to be defined. Among today's challenges, one of them is to find how to effectively integrate heterogeneous data sources, i.e., deployed new technological IoT solutions with traditional SC systems and a third-party software component. To address this issue, a global ontological approach from the perspective of the whole DSC is required.

This article focuses on the transparency aspect of the DSC model, taking into consideration the implementation of IoT-based technology. The main objective of this paper is to propose the IoT-based DSC model comprising four chain stages: milk production, milk transportation, milk processing, and dairy products distribution. Moreover, the comprehensive DSC domain ontology as a knowledge model is introduced. It is specified based on the domain business analysis and feedback from clients in the dairy industry. The proposed DSC ontology aims for improvement of the DSC management efficiency by enabling interoperability within DSC. The applicability of the proposed ontological model was verified using a case study, which estimates the environmental footprint at the milk transportation stage of the DSC.

Transparency of the DSC, possible due to the IoT technology, becomes a vital scientific aspect of the modern Supply Chain management. The proposed implementation of the transparent DSC model provides a basis for enhancement of supply chain management in terms of product-oriented safety (quality), visibility, optimization, and sustainability. It is also worth mentioning that the proposed ontology would facilitate the application of IoT solutions and enhance the applicability of sustainabilityoriented DSC management solutions that meet the European Dairy Association (EDA) and International Dairy Federation (IDF) recommendations.

\section{SURVEY OF RELATED WORKS}

\section{A. Supply Chain Modelling}

Food Supply Chain Management (FSCM) is a wide topic, which covers different activities and operations from food production by processing and distribution up to consumption. A feature of FSCM, which differentiates it from other types of SCM, is the need to assure sufficient quality and safety of transported products, which makes the process more complex and demanding in terms of Supply Chain Management.

There are various FSC models and approaches to FSCM [6], which mostly focus on Supply Chain efficiency, environmental impact, food quality, and safety. Sel, Bilgen, Bloemhof-Ruwaard, and van der Vorst address an issue of the production stage of the Dairy Supply Chain, in particular integrated production planning and scheduling problems [7]. The authors introduce a mixed integer linear programming formulation to integrate tactical and operational decisions. Moreover, to decompose time buckets of the decisions, a heuristic approach is proposed.

Another approach about how to increase production efficiency without compromising the environmental impact of DSC was addressed by Validi, Bhattacharya, and Byrne in [8]. They propose a sustainable two-layer Dairy Supply
Chain model aimed for cost minimization of the milk distribution system. They propose a sustainable distribution process enabling reduction of the total carbon emission from the transportation involved in the entire distribution in DSC. In [9], authors have the same research motivation. They propose an optimization model for the sustainable design of refrigerated automated storage and retrieval systems. The proposed model allows an analysis of parameter impacts, such as the storage temperature, the incoming product temperature, and the facility location on the energy use, costs, and carbon dioxide emissions.

Environmentally oriented modelling of the DSC was also proposed by Kirilova and Vaklieva-Bancheva in [10]. In this paper, the authors include three interconnected models for describing curd production, DSC and its environmental impact in terms of wastewater and $\mathrm{CO}_{2}$ emissions associated with the curd production and the transportation of raw material and products.

To increase food quality and safety, Zhong, Lin, $\mathrm{Wu}$, and Zhang propose the DSC traceability model to monitor and analyse the potential safety hazards in dairy production, processing, distribution, and sales process [11]. The proposed traceability platform, a so-called "pre-warning system", uses the Back Propagation Neural Network method to forecast the potential risks in Supply Chain stages. Alternatively, Yu and Nagurney developed a network-based Food Supply Chain model under oligopolistic competition and perishability, with a focus on fresh products, i.e., fruits, vegetables [12]. The proposed model includes inter alia food exponential time decay depending on the time duration and environmental conditions and the discarding costs associated with the disposal of spoiled food products.

\section{B. Traceability and Visibility in Supply Chain}

There are various definitions of traceability [13], however, it is worth quoting one specified by the European Union (EU) regulation 178/2002 (EU, 2002) [14], which concerns food industry by defining traceability as "the ability to trace and follow a food, feed, food-producing animal or substance intended to be, or expected to be incorporated into a food or feed, through all stages of production, processing and distribution." Traceability refers to information trial/record, which follows the food product's physical trial through various stages of a Supply Chain [15]. Visibility in SC may be realized continuously by tracking of objects within SC stages or discretely, i.e., focusing on some particular points in SC, e.g., transfer or pick-ups of goods/products [6]. Narrowed visibility is much more common, mostly due to the cost of its implementation and maintenance.

Provided high transparency of SC ensures deep food tracking from a retailer back to the sources through the SC trajectory. It is a significant advantage from the perspective of providing high quality and safe food products [13]. Moreover, visibility of SC is economically desirable because it ensures agility, just-in-time manufacturing and distribution, and lean operations, highly desirable features in today's SC [16]-[19].

Supply Chain product visibility may be defined as "the capacity of the Supply Chain to have a view of a product's 
lifecycle, from its conception, manufacturing, distribution, and delivery to the end customer, customer's experience of the product, and the product's end-of-life activities and processes" [16]. There are various Radio-frequency Identification-based (RFID) and barcode-based visibility architectures both commercial and academic. An implemented solution based on RFID tags and 2D barcodes improves efficiency and security of SC. An example solution applies real-time Automatic Identification and Data Capture (AIDC) systems in a wheat flour Supply Chain (collecting, processing, and packaging) [20] and Beef Supply Chain [21]. Barge, Gay, Merlino, and Tortia technologically investigate traceability properties of AIDC system handling in a dairy factory. In their paper, the following aspects are investigated: fixed and mobile RF devices operating at low, high, and ultra-high frequency bands considered for both static and dynamic identification of single/multiple cheese wheels. Moreover, tag type and shape, required power, antennas polarization and orientation, fixing method and ripening duration are considered in order to verify their effect on reading performance and system reliability [22].

\section{IoT in Supply Chain}

Internet of Things is the key concept, which provides visibility and enables interoperability between distributed systems in complex SCs. Therefore, today's management of integrated SC is evolving towards inter alia IoT cloud distributed solutions, blockchain transactions, and big data analysis of the traced information [23]. There are several examples of applying an IoT approach in different SCs aimed for efficiency and safety improvement [24], [25].

In [26], authors propose a knowledge model (ontology) providing a highly visible $\mathrm{SC}$, in which the location of individual things can be determined at any time by potential SC participants. The proposed solution assumes the application/adaptation of the IoT concept. Lou, Liu, Zhou, and Wang discuss the characteristics of the IoT in SC and possible enabling technologies. Moreover, they explored the distributed architecture of SCM over the IoT [27]. The IoT concept is a basis of the so-called "Industry 4.0 platform", which stands for the fourth industry revolution. It is also understood as a new level of organization and control over various SC industries and their product life cycle, as it is more optimized towards individualized customer needs [28]. IoT is also used to virtualize the food SC. It enables Supply Chain actors to monitor, control, plan, and optimize business processes remotely and in real-time based on virtual objects [29]. The authors propose an architecture to implement enabling information systems. The architecture is applied to a case study of a Fish Supply Chain.

\section{Food Supply Chain Ontology}

There have been various studies concerning food Supply Chains presenting different kinds of ontologies applied to provide a common understanding of conceptual knowledge. Pizutti and Mirabelli present Food Track \& Trace Ontology dedicated to improve the management of information for food chain traceability. The proposed ontology provides the proper information in case of food accidents or food outbreak diseases [30]. Another example of food-related ontology in the food Supply Chain is Meat Supply Chain Ontology (MESCO) [31]. Authors analyse the problem of meat traceability along the whole Supply Chain, from the farmer to the final consumer. The proposed solution enables interoperability among different systems and allows for integrating the heterogeneous databases adopted by each actor involved in the Supply Chain. Various aspects of Dairy Supply Chain quality management practices are represented by static and social ontologies [32]. The static ontology represents various kinds of entities of complex relationships, while social ontology represents the product and quality relationships among organizations in the Dairy Supply Chain. Yue et al. discuss the use of ontology as a knowledge base, i.e., concepts and their relationships in the Vegetable Supply Chain [33]. Another variation is the ontological framework providing contextual, as well as scientifically correct, information regarding crop production lifecycle [34]. The ontology may also be used as a source of reliable nutrient data available in other systems. For this, a food-oriented ontology (FOODS) was proposed, which consists of concepts of ingredients, nutrients, substances, etc., defining the semantics of nutritional facts [35].

An example of Food Supply Ontology may be also covered by the dairy domain. In [36], authors have constructed a domain-specific dairy ontology, which provides a controlled vocabulary to describe dairy products and corresponding potential hazards associated with dairy products. Another research concerns the linked data mechanisms as a solution directed for this semantic interoperability problem. Therefore, it was developed the Common Dairy Ontology (CDO), which serves the semantic interface to applications for dairy farming decision-making and analysis and enables the reasoning on the dairy concepts [37].

\section{PRoblem Statement And ObJectives}

The review of related works shows that the rapid development of the IoT concept and its growing applicability significantly affect SCM of today, regardless of the type of products. A new way of SCM assumes high visibility of raw materials, components, products, and processes at all SC stages. The main goal of visibilityoriented solutions is to increase the effectiveness, reliability, and sustainability of the Supply Chain. Modern SCM may be carried out in the IoT ecosystem (see Fig. 1), which provides a digital representation of SC used for the value chain supporting activities related to inter alia firm infrastructure, human resources, and procurement. There are also many other technological supporting activities, which significantly increase operational capabilities of the value chain, e.g., by improving quality of produced goods, transactions security or building awareness of the end customer. However, a comprehensive approach to the problem is still lacking, especially in the field of Dairy Supply Chain. There are no clear and meticulous guidelines on how to provide the DVC supportive activities.

Building the Dairy Value Chain supported by the digital transformation of the dairy industry is the leading strategy 
of European and global international dairy organisations, such as EDA and IDF. Such institutions provide recommendations and requirements on what types of technological supportive activities should be found in the modern DVC. The common recommendation of both organisations is sustainable development by environmental footprint monitoring of dairy products as an example of DVC supportive activity.

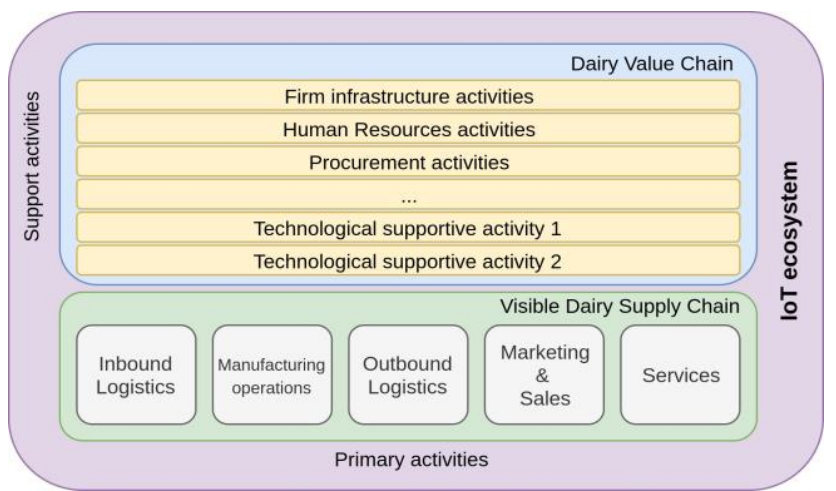

Fig. 1. Visible Dairy Supply Chain and Dairy Value Chain in the IoT ecosystem.

Each DSC has its own structure and characteristics; therefore, its visibility enhancement needs to be tailored to a specific production plant, existing regulations, and market demands. However, for this reason, to show the whole visibility of the DSC could be challenging. The current visibility models cover just part of DSC, mainly the final stages, i.e., distribution and retail of dairy products. However, the dairy farmers and transportation companies providing milk hauling and milk processors have not yet been included, but should also be visible in the Supply Chain. It seems that a unified IoT-based DSC model showing the possible relations among DSC entities and indicating devices, tools, and places would enhance such efforts. Therefore, there is a great need to define the ontology showing the enable interoperability among all DSC participants. Such ontology would facilitate the implementation of IoT solutions and enhance the applicability of sustainability-oriented DSC management solutions that meet the EDA and IDF recommendations [38], [39].

There exist some ontologies, which deal with intelligent farming applying IoT technologies for managing milk production or cattle breeding [37], [40]-[42]. However, they do not concern the milk supply chain defined as a stage between milk production and dairy products delivery to the consumer. Nevertheless, the Dairy Supply Chain consists of several main stages that can be considered separately as a field of knowledge, e.g., transportation, medical tests, dairy products production, etc., which combining an ontology with IoT technologies enables monitoring of each stage of the process by mean of digitized environment. For instance, the vehicle's sensor data provide information about shipment conditions, such as cargo temperature, geolocation, cargo contamination, trip time, etc. The data provide additional information like Product Environmental Footprint (PEF) values or overall statistics. The proposed inclusion of the milk supply chain establishes an opportunity to create a product tracking history for tracing purposes. The historical data useful for statistics could help investigate the specific cases in the past and find out where and how often they happened.

The main objective of this paper is to propose and implement the IoT-based Dairy Supply Chain model. The model facilitates holistic visibility in the four chain stages: milk production, milk transportation, milk processing, and dairy products distribution. Furthermore, the proposed visible IoT-based DSC model is implemented in the comprehensive IoT-based Dairy Supply Chain ontology. The introduced IoT-based DSC ontology aims to endeavour interoperability within DSC. It also aims to improve DSC management in terms of product-oriented safety (quality), visibility, and sustainability.

The main contribution of this paper is an ostensive definition of the IoT-based Dairy Supply Chain model, including a detailed description of the four chain stages: milk production, milk transportation, milk processing, and dairy products distribution. The proposed IoT-based DSC ontology is founded on the EAGLET ontology model [26]. The applicability of the proposed ontological model is verified in the case study, which estimates the environmental footprint at the milk transportation stage of the DSC.

\section{MOdELling OF Visible DAIRY SUPPly CHAIN}

The typical DSC includes seven life cycle stages: feed production, milk production, milk transportation, packaging, non-dairy ingredients supply, milk processing, dairy products distribution, use stage, and end of life, which are represented in the general DSC model shown in Fig. 2. Packaging and non-dairy ingredients supply are not included in the diagram since they are considered as separate life cycle stages. Nevertheless, the outputs of both non-included stages provide distinctive properties to the final dairy product. Also packaging type, size, and shape are key components differentiating brands in the dairy industry [38].

Since the current visibility within the feed production-, use-, and end of life-stages are technically limited, this study has to be narrowed to the four major stages, i.e., milk production, milk transportation, milk processing, and dairy products distribution. In this section, these four stages are described with emphasis on corresponding systems enabling DSC's visibility.

\section{A. Milk Production}

Dairy cattle rearing is the main process on the farm within the milk production stage. Management of dairy cattle is usually shaped by the dairy market requirements, established regulations, and current trends. Generally, the management may be realized indoor, outdoor or within a mixed rearing system. Housed dairy cattle usually spend their time in tie stall or free stall barns, while outdoor dairy cattle spend whole days grazing, usually on pasture. The mixed system can combine these two patterns in accordance with yearly seasons. The system used mostly depends on the climate and available land around the farm. For all dairy cattle rearing systems, cattle visibility in terms of activity 
and health status may be realized by integrated cattle monitoring systems [43].

The main process during rearing is feeding where dairy cattle typically spend about from 4 to 6 hours per day. Forages (silages, hay, straw) and concentrates (soy, rape, cereal grains, feed additives and their proportion in the diet), which comprise proteins, fats, carbohydrates, vitamins, and minerals, are given to the herd according to the recipe. Dairy farmers usually work with nutritionists to create a feed ration that is best suited for their herds. To ensure dairy cattle feeding visibility in the indoor rearing system, corresponding feed monitoring systems are implemented.

Usually, on most dairy farms, milking is done by milking machines, which sucks the milk out of the teat by a vacuum pump. There are also more sophisticated solutions dedicated to big farms, explicitly automatic milking systems also known as milking robots, which allow complete automation of the milking process and enables qualitative and quantitative visibility of the process.

Fresh milk from a healthy cow is practically free from bacteria, but must be protected against infection as soon as it leaves the udder. Therefore, milk is chilled quickly to about $4{ }^{\circ} \mathrm{C}$ immediately after it leaves the cow. Cooling equipment, which is a built-in bulk tank, and heat exchangers are designed to guarantee to chill to a specified temperature within a specified time. These tanks are also often equipped for automatic cleaning to ensure a uniformly high standard of hygiene [44]. The cooling performance and cleaning processes of the cooling tank may be monitored by a corresponding milk quality monitoring system integrated with milk bulk tanks.

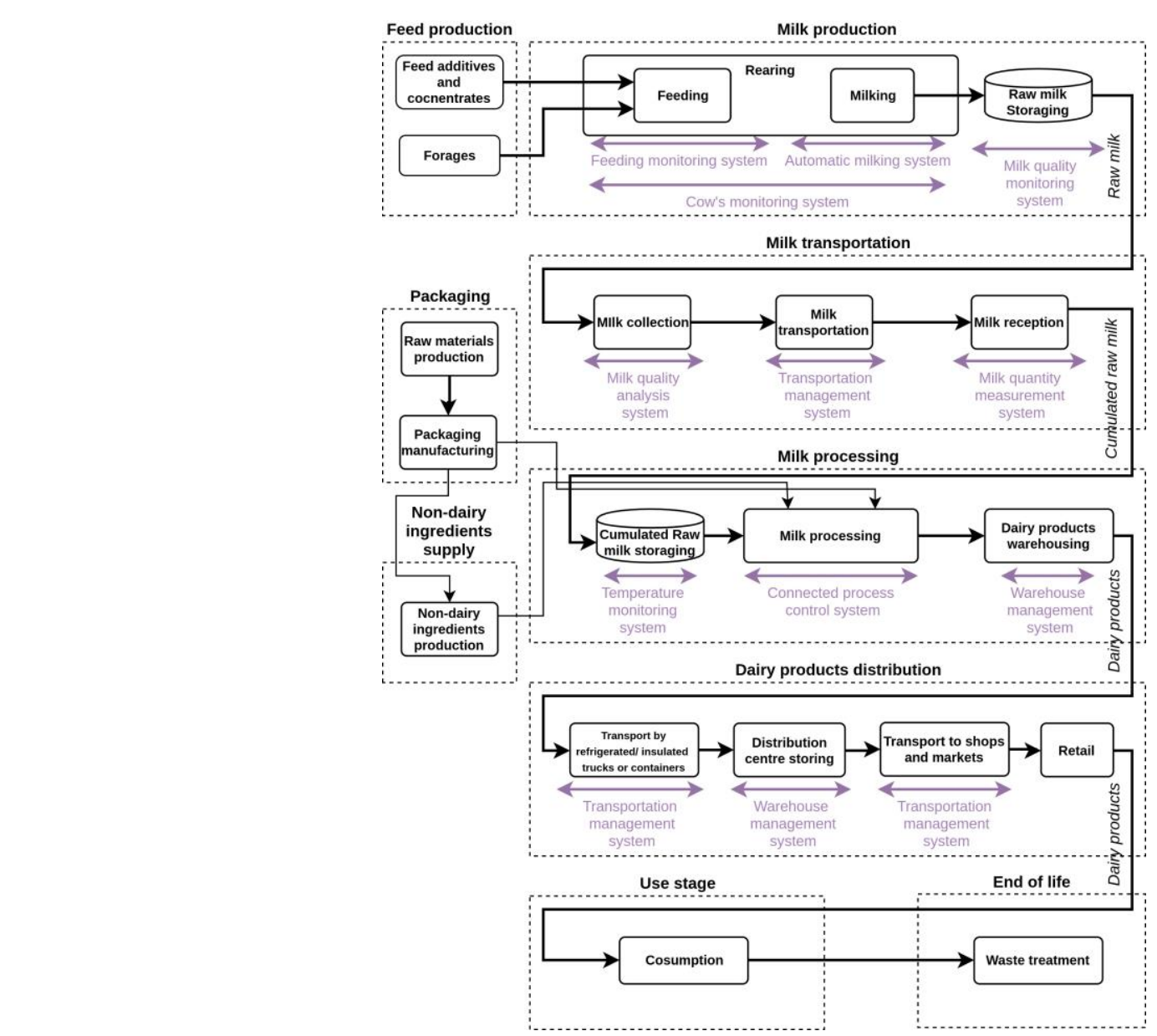

Fig. 2. Dairy Supply Chain model.

\section{B. Milk Transportation}

The milk hauling companies transporting fresh, raw milk provide services for the dairy company, using their fleets of milk bulk tankers (also known as milk hauliers) and drivers. Depending on the size of the dairy plant and the number of suppliers, there is a need for several transportation companies to realize daily transport plans. To facilitate management of milk collection and make it more efficient, each milk bulk tanker is equipped with a transportation management system used to monitor the position and report occurred milk collection events [17].

Milk receiving starts from the connection of the loading hose from the tanker to the outlet valve on the farm cooling tank. The milk is pumped into the vehicle's milk bulk. In the meantime, a representative milk sample is taken and stored in the refrigerated chamber in the milk haulier for further laboratory examination taken in the dairy plant laboratory [45]. The tanker is usually fitted with a flow meter and pump so that the volume and temperature are automatically recorded. Pumping is stopped as soon as the cooling tank is empty. When the tanker has completed its scheduled round, it delivers the milk to the dairy [19], [44].

To increase the visibility and quality of the milk transfer between two stages/chains in the DSC, there is a need to assess the quality of the milk. In order to assess the received 
milk quality, the milk haulier is equipped with a milk quality analysis system, which monitors inter alia the temperature, $\mathrm{pH}$, and quantity of received milk, and information is transmitted to the data centre.

According to the transportation schedule, a milk haulier picks up milk from declared milk farms. The transportation route is finished in the dairy plant. Dairies have special reception departments equipped with dedicated monitoring systems to handle the milk brought in from the farms. The first thing done at reception is to determine the quantity of the milk, which is done by the milk quantity measurement system realized either by weighting systems or by flowmeters. When the milk is pumped out from the vehicle tanks, the milk haulier executes a cleaning procedure, i.e., a milk tank, pump, hose, and fittings of this milk haulier are properly washed and sanitized before the next collection [44].

\section{Milk Processing}

The raw milk is pumped out from the milk bulk tanker to the large vertical milk silo tanks, which have capacities from about 250001 up to 1500001 . Such silo tanks are of doublewall construction, with insulation between the walls, and due to their size, they are usually located outdoors [44]. Each milk silo tank is equipped with propeller agitators and temperature monitors.

Milk processing is a complex multi-staging technological process, in which raw milk passes through several stages of treatment before reaching the dairy cooling warehouse in the form of a final, refined dairy product. The milk production is a continuous closed process, which is customized in terms of the output dairy product. Due to the market requirements, for each dairy product type, there are various representations, e.g., lactose-free, non-GMO, organic, etc., for which the process is modified. Therefore, it is impossible to model a general dairy plant processing scheme. It must be approached specifically [38], [44].

However, some general processing stages, common for all technological processes and corresponding output dairy products, can be specified. In the beginning, raw milk from the silo tanks is mechanically cleaned in the separation process. Afterwards, the milk is homogenized, when fat globules and their clusters are splitting and dispersing to smaller sizes. Pasteurization is another basic pre-treatment operation in the milk processing, which involves heating milk to a specific temperature for a specified period of time and cooling it again without allowing recontamination. Further processing steps like microfiltration, Ultra-High Temperature (UHT) treatment, and mixing or culturing milk for flavoured and yoghurt products can be also specified. One of the latest technological steps is dairy product packaging using automatic packaging machines, which fill and package all produced dairy products into paper cartons, plastic bottles or other packages. Next, on the assembly line, the expiry date is printed on each product. When packaged into cartons, milk products are transported into cooling warehouses, which store all products at the recommended temperature. To provide high quality dairy products, the production processes are also monitored. Therefore, process control equipment and monitoring systems provide a possibility for adaptation of the IoT concept, simultaneously increasing the visibility of the process [46].

Dedicated warehouses located in the dairy processing plant receive dairy products from the processing plant production line and store goods according to the internal warehouse storage system. Storage and handling of manufacturing goods in dedicated storage spaces are performed in a controlled environment coordinated by the warehouse management system.

There is also an independent process of raw milk laboratory testing and examination. Milk samples taken from each farmer are tested for inter alia antibiotics, milk fat, protein, somatic cell count, and bacteria. Based on the milk quality and its composition, it is graded, which influences the farmer's payment [44], [45].

\section{Dairy Products Distribution}

According to the transportation order, dairy products from cooling dairy warehouses are selected/picked up and loaded on cargo vehicles, e.g., big refrigerated or insulated trucks, which carrying capacity exceeds 16 tons of refrigerated containers. Then the cargo is sent to domestic distribution centres, wholesalers' warehouses or can be exported abroad. Regardless of the transportation mode, temperature control is a vital component in dairy transportation in order to provide continuity of the cold chain. Therefore, the vast majority of transportation services is carried out by temperature-controlled transport. Currently, most of the transport vehicles providing distribution of dairy products are equipped with transportation management systems enabling transportation transparency, i.e., truck location, transportation conditions, etc.

At the destination place, dairy products are unloaded into cold storage warehouses. To ensure adequate storage conditions, the environment is coordinated by dedicated warehouse management systems. From these places, dairy products are redistributed for local retailers/markets. The transport to markets is usually done by medium road transportation carrying capacity between 1.5 tons and 16 tons or small road transportation carrying capacity below 1.5 tons. Transportation services are carried out by temperature-controlled vehicles or insulated trucks. The transportation is also equipped with transportation monitoring systems providing information about the carried out transportation task.

\section{ONTOLOGY OF DAIRY SUPPly CHAIN}

The knowledge model representing a visibility-oriented DSC domain presented in the DSC model is covered by the proposed DSC ontology. The DSC ontology is composed of basic DSC processes. Each process and its related properties may be described by the DSC ontology unit shown in Fig. 3. This model describes relationships among the basic Process class and properties represented by classes: Actor, Location, Instrumentation, Product, and Tool. To distinguish the classes representing the process's properties, each class is coloured distinguishably.

The proposed ontology presented in a DSC ontology diagram in Fig. 4 includes four main phases, i.e., milk production, milk transportation, milk processing, and dairy 
products distribution with consecutive processes in each phase.

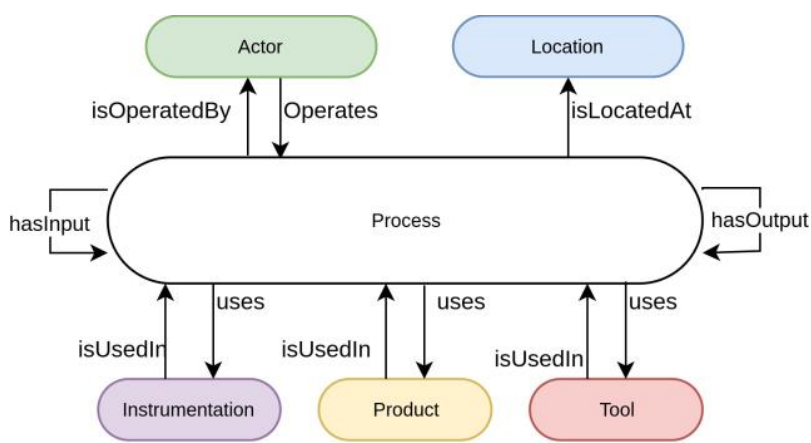

Fig. 3. Dairy Supply Chain ontology unit based on [26].

This chapter focuses on the background of the DSC domain-oriented ontology and its implementation.

\section{A. Dairy Supply Chain Ontology as a Dairy Domain Representation}

The DSC ontology diagram presented in Fig. 4 defines a DSC model and may be treated as a semantically oriented domain standardization. This model contains elementary domain knowledge and might be treated as a reliable basis for extending or combining with other ontologies. It may be handled either by merging or alignment [47] processes.
Reported researches [48]-[52] and results of EU R\&D projects [53]-[57] prove that semantic technologies are worth exploring as an approach to integrate heterogeneous data sources. The integration is important from the DSC point of view because the whole Supply Chain is handled by various, heterogeneous systems, which are based on different technologies. Since the main goal of creating the DSC ontology is to unify the whole process in order to support Dairy Value Chain services, i.e. establishing the product history (footprint), the DCS ontology can be used as a basis for other ontologies that operate within the DSC domain.

After defining the DSC model, the next step is to apply it to create an ontology file. There are two common standards to be used. The first one is Resource Description Framework (RDF) [58] and/or RDF Schema [59]. The second standard is Web Ontology Language (OWL) that contains three versions: Lite, DL, and Full [60]. The RDF is sufficient to define the DSC vocabulary, i.e., a formal naming and defining types, properties, and interrelationships of the entities that really exist in a particular domain. Nevertheless, it is decided that the OWL-Lite would be the better option to fulfil all goals of using the DSC ontology because its vocabulary is richer, and therefore that allows defining the model more accurately.

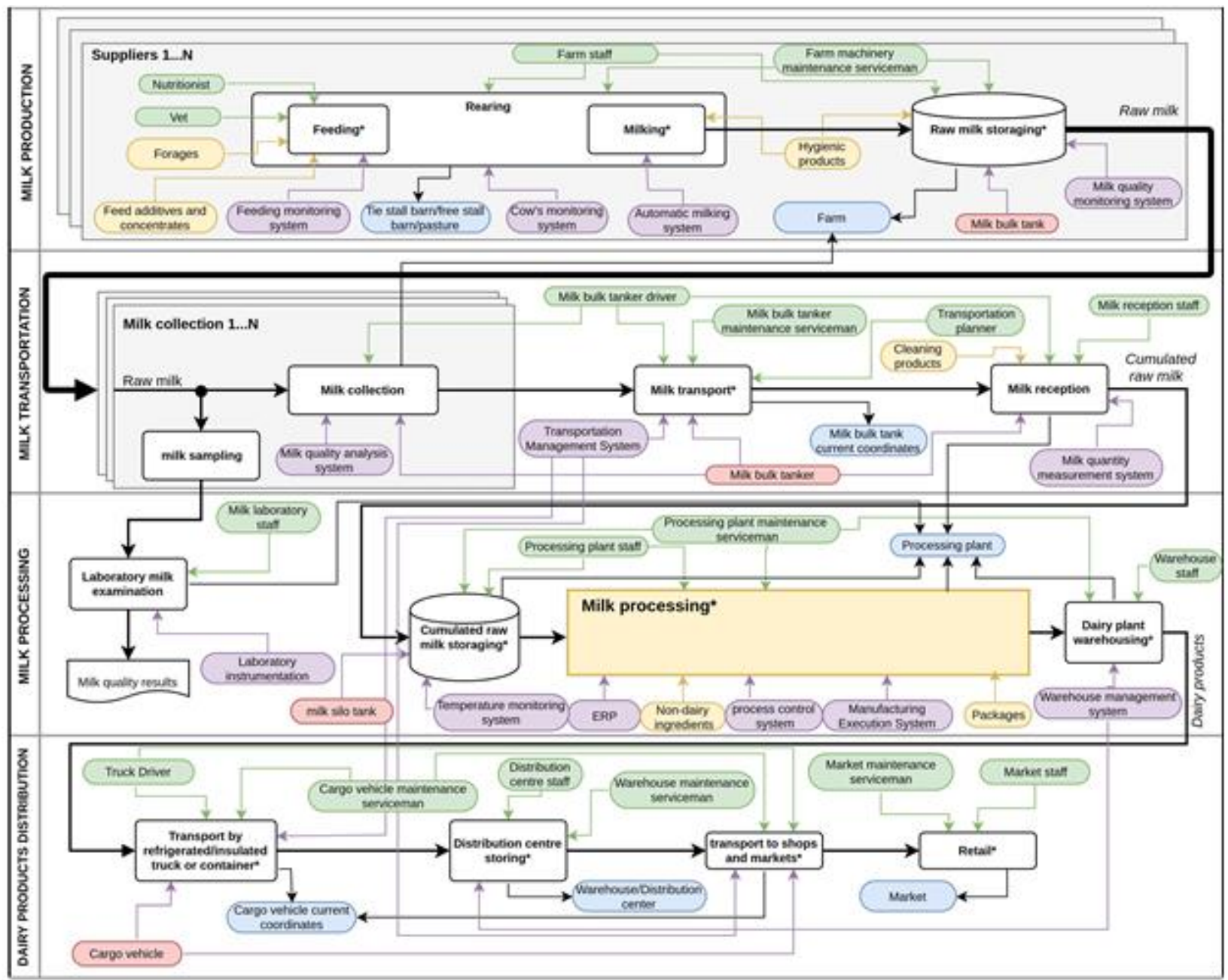

- maintenance and service related instrumentasion, products and voots included

Fig. 4. DSC ontology diagram. 


\section{B. The Dairy Supply Chain Ontology Implementation}

In order to create DSC ontology, the Protege (v.5.5.0) [61] is used. The DSC model, depicted in Fig. 4, is mapped into the OWL structures by defining classes and object properties according to the model unit presented in Fig. 3. The classes describe objects/entities, which define the domain, whereas object properties describe relations among the classes.

According to the OWL standard, the core of every ontology is a root class: "owl:Thing". Therefore, every class is a subclass of Thing. A very first step to create the DSC ontology is to convert objects from the DSC model unit (Process, Actor, Location, Instrumentation, Product, and Tool) presented in Fig. 3 into Thing subclasses. Figure 5 depicts these classes and their hierarchy. Colours of nodes are preserved in order to show the similarities between the model and ontology. Each of these classes is abstractive, i.e., does not contain any instances; nevertheless, they have subclasses that specifically define individual elements of the DSC. For example, Fig. 6 depicts the subclasses of the Location class. This example shows that core classes are not the only abstract classes, but they also might contain abstract subclasses in order to group a set of entities with similar properties, e.g., RearingLocation. Therefore, the next step of creating the DSC ontology process is to append all subclasses of each abstract class in order to define all objects that describe the DSC domain in details.

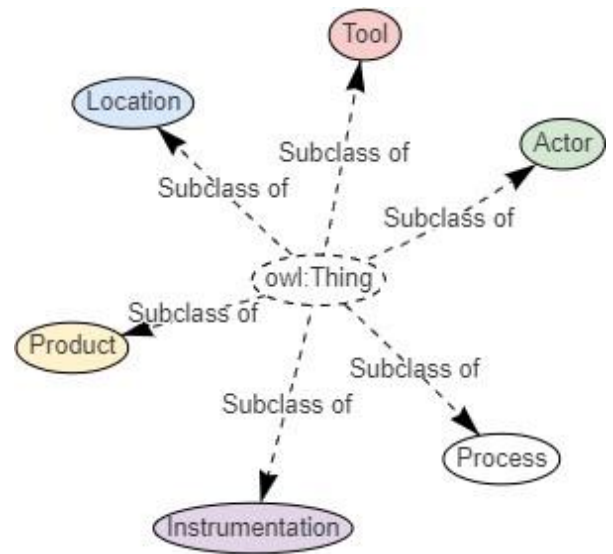

Fig. 5. Core classes of the DSC ontology.

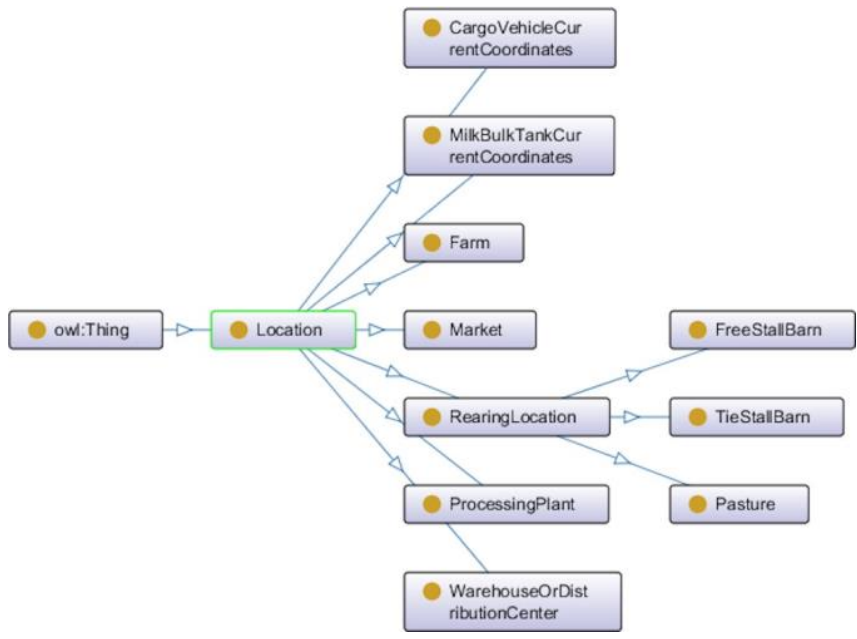

Fig. 6. Subclasses of Location abstract class.

To define the relationships between the ontology classes (edges between the nodes in the DSC model), object properties are used. It is worth mentioning that only nonabstract classes (DSC entities) are linked via object properties. Each relationship between the subclasses (see Fig. 7) is created by using the property restrictions [60] as to define the value and cardinality constraints. For example, the restriction some (owl: someValuesFrom), which must be used to define that MilkTransport process, is operated by at least one MilkBulkTankerDriver actor. Using this restriction, the edge between the MilkTransport and MilkBulkTankerDriver can be defined.

Figure 7 (DSC model unit) shows that the classes (except subclasses of the Location class) contain bidirectional edges that allow one to search forward and backwards in the DSC process. In order to define a bidirectional edge (object property) in the OWL, the owl:inverse Of [60] construct is used, which describes inverse relations between the classes.

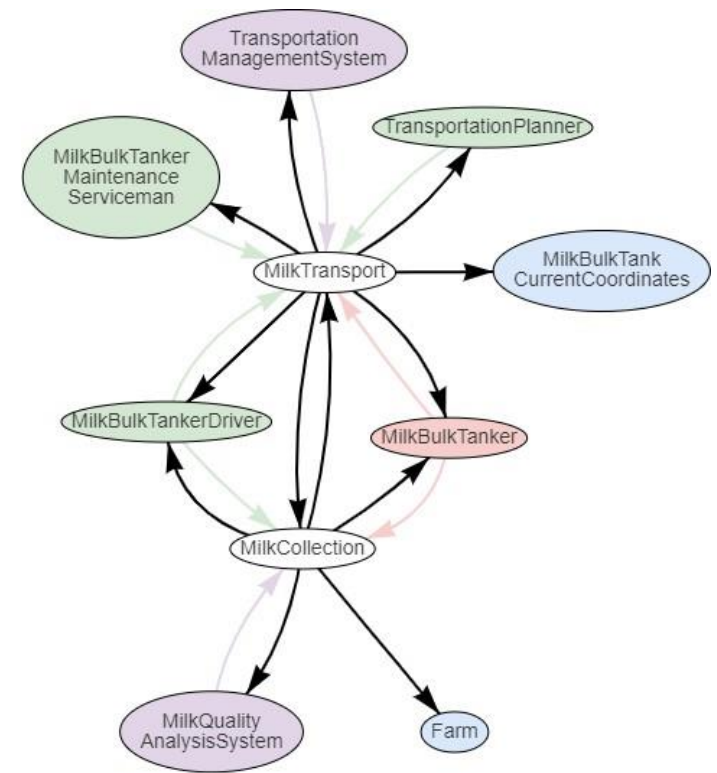

Fig. 7. The subgraph of DSC ontology - the relations of two processes (Milk Collection and Milk Transport).

Moreover, Fig. 7 shows a subgraph of a Milk Transportation stage. There can be seen relationships among the processes, as well as DSC elements that are in relation to these processes. Due to the complexity of the graph, the labels of the edges are omitted, but they are marked with the same colours as in the diagram of DSC model unit (Fig. 3).

\section{Case Study: Evaluation of Product ENVIRONMENTAL FOOTPRINT FOR THE DAIRY SUPPLY CHAIN TRANSPORTATION STAGE - ONTOLOGICAL APPROACH}

An example supportive activity in DVC, which is enabled due to visible DSC, is related to sustainability-oriented EUpolicy focusing on Product Environmental Footprint of dairy products. Considering the application of the proposed DSC ontology, the presented case study concerns the complex global problem of PEF estimation in the DSC, which is used to evaluate and report products' life cycle environmental impacts. The PEF is a structured systematic approach to assess the quality of DSC operation in terms of sustainability that is highly promoted by the EU.

An environmental impact of the Supply Chain is one of 
the major constraints of sustainable development on the dairy industry. The EU is committed to the Sustainable Development Goals defined by the UN aiming for urgent action to combat climate changes and their impacts. This commitment is included in EU agricultural policy [62], in the context of sustainable management of food production to ensure sustainable consumption and production patterns. However, there is a need to define sustainable and comprehensive measures of the dairy industry's environmental impact [63].

One of ways to assess the quality of DSC operation in terms of sustainability is by applying the dairy PEF estimation and monitoring in all stages of DSC. The EU commission has provided Product Environmental Footprint Category Rules (PEFCRs) as specific guidance for PEF studies, at the level of a particular product category, for calculating and reporting products' life cycle environmental impacts [64]. PEFCR for dairy products covers the full life cycle for dairy products sold on the European and European Free Trade Association (EFTA) markets [38]. It evaluates the environmental impacts by applying a structured systematic approach in order to get comparable results.

For this reason, it is essential to monitor and estimate the impact of DSC on the environment, which could be significant in terms of sustainable development. The DSC's impact on the environment needs to be represented by sets of data from each stage of DSC (see Fig. 2). Therefore, such impact, understood as PEF estimation, requires aggregation of data from heterogeneous data sources according to the official requirements [38], [64].

In this paper, we apply PEF narrowed just to one DSC stage - transportation, as a case study to validate our proposals. For the purpose of PEF analysis in DSC, the fundamental issue is to determine the period within which PEF needs to be estimated. Due to the system of daily pickups in the dairy sector, daily PEF estimation seems to be a reasonable time period.

To estimate the PEF from the transportation stage of a particular DSC, the following processes related to transportation need to be monitored: milk collection, transportation, and milk reception. Acquired and aggregated data are used to calculate the PEF component according to [38], [64].

According to the transportation schedule, every day in each route, milk bulk tankers pick up milk from declared milk farms. Each transportation route starts either from the transportation company location or from the dairy plant and finishes in the dairy plant in the reception department. Every day collection of all milk suppliers is carried out by a specific number of milk bulk tankers that carry out a fixed number of routes. Therefore, to estimate the aggregated daily transportation PEF component, all milk collection routes need to be analysed separately. Thus, for each transportation route, the PEF component needs to be calculated according to predefined rules [38], [64]. Furthermore, to estimate the daily transportation PEF component, interoperability and synchronization among DSC participants, i.e., milk supplier, transportation company, and dairy plant departments, need to be established.
Based on the proposed model, Table I summarizes the basic information from considered transportation processes, which are required to estimate the transportation PEF component. From the table, one can see, that to estimate the transportation PEF component, there is a need to aggregate data form heterogeneous data sources like the milk suppliers' database, on-board device on the milk hauler, milk quality analysis system, transportation database, milk quantity measurement system at the reception department, and tank cleaning system at the cleaning station. For this purpose, a unified information model needs to be determined.

\begin{tabular}{|c|c|c|}
\hline $\begin{array}{c}\text { Transportation } \\
\text { stage }\end{array}$ & Information & Data source \\
\hline \multirow{3}{*}{ Milk collection } & $\begin{array}{l}\text { Milk supplier details as } \\
\text { location, rearing system, } \\
\text { number of cows, etc. }\end{array}$ & $\begin{array}{l}\text { Milk suppliers' } \\
\text { database in the } \\
\text { dairy billing and } \\
\text { planning } \\
\text { department }\end{array}$ \\
\hline & Received milk quantity & $\begin{array}{l}\text { On-board device on } \\
\text { the milk bulk tanker } \\
\text { as a component of } \\
\text { the Transportation } \\
\text { Management } \\
\text { System }\end{array}$ \\
\hline & Received milk quality & $\begin{array}{l}\text { Milk quality } \\
\text { analysis system } \\
\text { from a dairy } \\
\text { laboratory }\end{array}$ \\
\hline \multirow{2}{*}{$\begin{array}{c}\text { Milk } \\
\text { transportation }\end{array}$} & $\begin{array}{l}\text { Route details from each } \\
\text { transportation segment } \\
\text { (distances between } \\
\text { collection points, average } \\
\text { speed) }\end{array}$ & $\begin{array}{l}\text { On-board device on } \\
\text { the milk bulk tanker } \\
\text { as a component of } \\
\text { the Transportation } \\
\text { Management } \\
\text { System. }\end{array}$ \\
\hline & $\begin{array}{l}\text { Milk bulk tanker details as } \\
\text { model, curb weight, max } \\
\text { payload, tank type (cooling } \\
\text { or isolated), production date, } \\
\text { compliance with European } \\
\text { emission standard for } \\
\text { exhaust emission, etc. }\end{array}$ & $\begin{array}{l}\text { Transportation } \\
\text { database in the } \\
\text { Transportation } \\
\text { Management } \\
\text { System }\end{array}$ \\
\hline \multirow[t]{2}{*}{ Milk reception } & $\begin{array}{c}\text { Total milk quantity brought } \\
\text { to the dairy reception } \\
\text { department }\end{array}$ & $\begin{array}{l}\text { Milk quantity } \\
\text { measurement } \\
\text { system at a } \\
\text { reception } \\
\text { department }\end{array}$ \\
\hline & $\begin{array}{l}\text { Amount of used cleaning } \\
\text { products for washing and } \\
\text { sanitizing of the tank }\end{array}$ & $\begin{array}{c}\text { Tank cleaning } \\
\text { system at a cleaning } \\
\text { station }\end{array}$ \\
\hline
\end{tabular}

To provide a solution aimed to estimate PEF components for each stage of DSC, according to PEFCR [64], the DSC ontology seems to be the suitable step into an efficient integration. In Fig. 8, a subgraph of the DSC ontology represents the three processes in the transportation stage, i.e., milk collection, transportation, and reception, which contribute to PEF component estimation. The subgraph also presents staff, vehicles, used products, and corresponding locations involved in milk transportation processes that can be associated with specific processes.

To estimate the PEF component from the transportation stage, data have to be aggregated via IoT devices enabling visibility, which are mounted in the milk bulk tankers, 
quality analysis systems in the laboratory, and the quantity measurement system in the dairy reception department. Complementary data required in the PEF component estimation may come from Transportation Management System databases provided by milk hauling companies. Figure 8 proves usefulness of the knowledge model to efficiently integrate mentioned data sources.

\section{CONCLUSIONS}

\section{A. Results Discussion}

The presented knowledge model representing a visibilityoriented DSC domain is realized by the proposed DSC ontology. It consists of basic processes occurring in the DSC and their related properties. This general model describes relationships between the basic Process class and properties represented by the following classes: Actor, Location, Instrumentation, Product, and Tool. The proposed DSC ontology is based on the Supply Chain-oriented EAGLET ontology model [26].

The proposed ontology represents a semantics approach that enables transparency of the DSC and endeavour's interoperability between heterogeneous data sources distributed across the Supply Chain to improve the DSC management efficiency and ensure sustainability analysis. Therefore, the proposed domain-oriented knowledge model matches well with the corresponding solution for integration and synergy-enabling purposes. Such generic ontology also enables interoperability among systems deployed in different industrial fields.

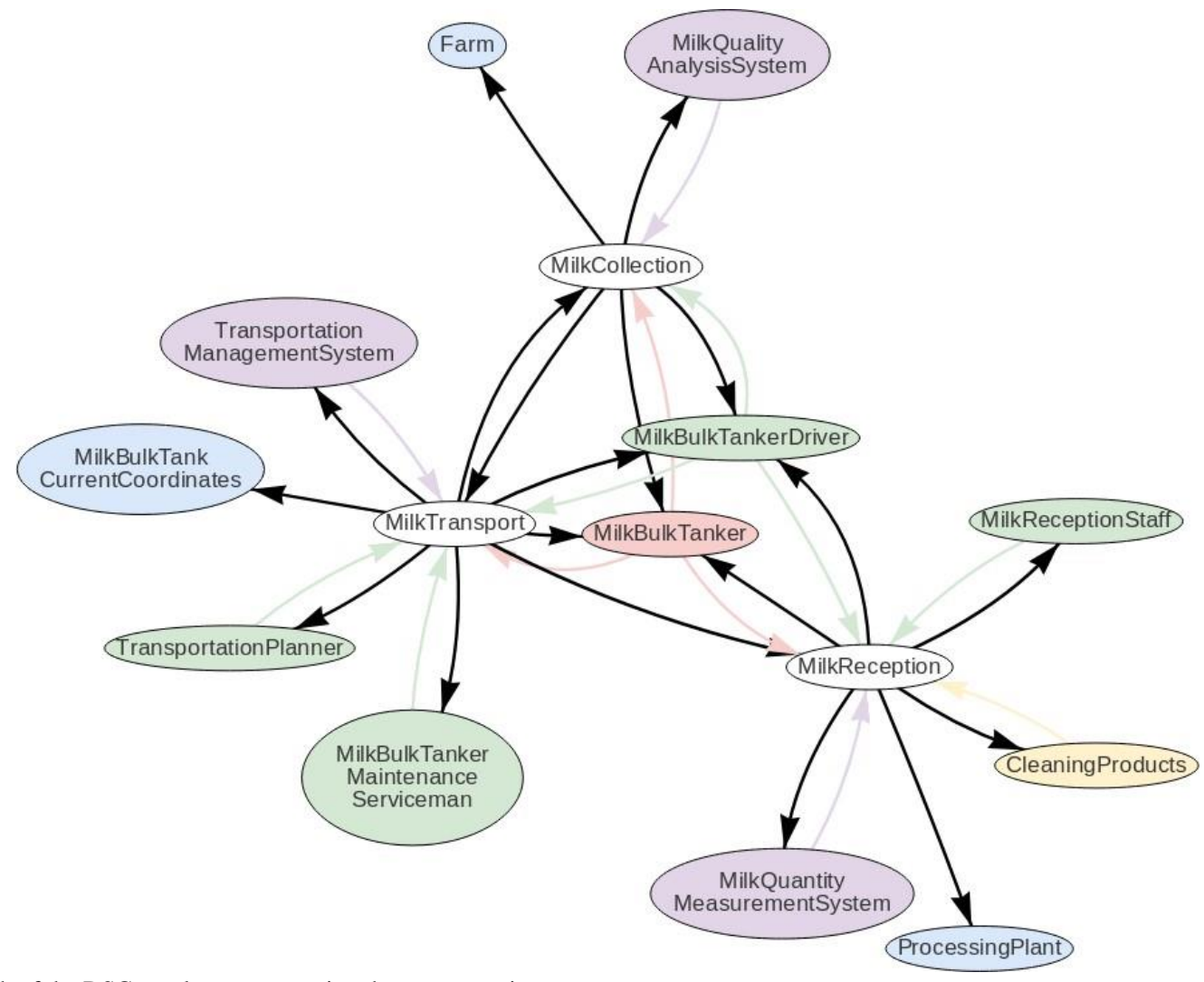

Fig. 8. A subgraph of the DSC ontology representing the transportation stage.

The applied DSC domain ontology results in an improvement of interoperability among DSC participants in the SC. Wherefore, collaborative actions between SC entities may be carried out, e.g., predictions and decision making understood as a Dairy Value Chain. The DSC ontology may be seen as a semantically oriented domain standardization. The proposed ontological model contains elementary domain knowledge and might be treated as a reliable basis for extending or combining with other ontologies by merging or alignment. The proposed generic approach enables semantic solutions for multi-domain applications.

The applicability of the proposed ontological model was verified using a sustainability-oriented case study. The case study concerns the complex global problem of Product Environmental Footprint estimation in the DSC. To achieve the PEF estimation goals, interoperability between various data sources within the DSC must be ensured.

This EU promoted approach aimed to assess and report products' life cycle environmental impact is especially important in terms of sustainability of the DSC. In the case study, an estimation of the environmental footprint at the transportation stage of the DSC was performed.

\section{B. Findings}

In the sub-section, the proposed DSC model consisting of the four major stages, i.e., milk production, milk transportation, milk processing, and dairy products distribution is described and relevant technologies, which enable DSC's visibility, are considered. Currently, due to technical reasons, the visibility within the feed production-, use-, and end of life-stages is limited. One of the prerequisites enabling visibility in feed production is development of infrastructure mostly at farms, which can 
facilitate tracking of sub-products and ingredients used for dairy feed production. Visibility in use- and end of lifestages might be possible if dairy products would be packed in identifiable packages.

This article focuses on the transparency of the Dairy Supply Chain (DSC), which is facilitated by an implementation of IoT-based technology. The main objective of this paper was to propose the holistic IoT-based DSC model, which enables full visibility at all DSC stages. Furthermore, based on the proposed model, the comprehensive IoT-based DSC ontology was formulated. The aim of creating this ontology was to define the DSC domain knowledge in order to support data interoperability within the dairy industry ecosystem.

The introduced ontology could be the foundation for the next generation Digital Supply Chain, concentrated in the dairy domain. It facilitates an implementation and scaling, but also interoperability of advanced digital technologies, i.e., artificial intelligence, blockchain, machine learning, and predictive analytics, which provide significant improvements to traditional SCs. These technological tools supporting connectivity enable secure collaboration of SC entities and provide comprehensive analytical opportunities in the SC. Both digitalization and provided intelligence in the Supply Chain lead to increased SC reliability and higher operational effectiveness, along with sustainable development.

\section{Future Work}

The presented research shows many application possibilities across the DSC related to digital transformation. One of the future research examples on DSC knowledge modelling concerns extension of DSC ontology or combination with other ontologies, i.e., farming, transportation, milk processing, distribution, and IoT by corresponding ontology merging or alignment. Such an approach will increase its applicability and integration possibilities.

Milk processing is a complex multi-staging technological process and uses customization in terms of the output dairy product. Therefore, to extend the proposed visible DSC model, the dairy processing stage of DSC can be modelled in more detail to represent production processes of particular types of dairy products. Then, as a result, for modelled dairy products production, PEF estimation and monitoring will be possible.

Future work may also focus on the PEF in order to increase its operational reliability and efficiency. Since at each stage of SC the corresponding PEF pilot models and PEF calculation guides [38], [64] are available, this approach might be verified experimentally within the corresponding environments. Moreover, estimation of PEF production from multiples stages of DSC using an efficient integration of multiple heterogeneous data sources seems to be an interesting technological challenge.

\section{CONFLICTS OF INTEREST}

The authors declare that they have no conflict of interest. The funders had no role in the design of the study; in the collection, analyses or interpretation of data; in the writing of the manuscript or in the decision to publish the results.

\section{REFERENCES}

[1] T. A. Gardner et al., "Transparency and sustainability in global commodity supply chains", World Dev., vol. 121, pp. 163-177, Sep. 2019. DOI: 10.1016/j.worlddev.2018.05.025.

[2] Siemens AG, Report "The Digitalization Productivity Bonus in Dairy Products Manufacturing", Siemens AG, Munich, Germany, Nov. 2017.

[3] M. E. Porter, Competitive Advantage: Creating and Sustaining Superior Performance. Simon and Schuster, 2008.

[4] P. Evangelista, C. Colicchia, and A. Creazza, "Is environmental sustainability a strategic priority for logistics service providers?", $J$ Environ. Manage., vol. 198, part 1, pp. 353-362, May 2017. DOI: 10.1016/j.jenvman.2017.04.096.

[5] M. K. Lim, M.-L. Tseng, K. H. Tan, and T. D. Bui, "Knowledge management in sustainable supply chain management: Improving performance through an interpretive structural modelling approach", J. Clean. Prod., vol. 162, pp. 806-816, Sep. 2017. DOI: 10.1016/j.jclepro.2017.06.056.

[6] R. Zhong, X. Xu, and L. Wang, "Food supply chain management: Systems, implementations, and future research", Ind. Manag. Data Syst., vol. 117, no. 9, pp. 2085-2114, Oct. 2017. DOI 10.1108/IMDS-09-2016-0391.

[7] C. Sel, B. Bilgen, J. M. Bloemhof-Ruwaard, and J. G. A. J. van der Vorst, "Multi-bucket optimization for integrated planning and scheduling in the perishable dairy supply chain", Comput. Chem. Eng., vol. 77, pp. 59-73, Jun. 2015. DOI: 10.1016/j.compchemeng.2015.03.020.

[8] S. Validi, A. Bhattacharya, and P. J. Byrne, "A case analysis of a sustainable food supply chain distribution system-A multi-objective approach", Int. J. Prod. Econ., vol. 152, pp. 71-87, Jun. 2014. DOI: 10.1016/j.ijpe.2014.02.003.

[9] A. Meneghetti and L. Monti, "Greening the food supply chain: An optimisation model for sustainable design of refrigerated automated warehouses", Int. J. Prod. Res., vol. 53, no. 21, pp. 6567-6587, Nov. 2015. DOI: 10.1080/00207543.2014.985449.

[10] E. G. Kirilova and N. Gr Vaklieva-Bancheva, "Environmentally friendly management of dairy supply chain for designing a green products' portfolio", J. Clean. Prod., vol. 167, pp. 493-504, Nov. 2017. DOI: 10.1016/j.jclepro.2017.08.188.

[11] H. Zhong, Ch. Lin, C. Wu, and G. Zhang, "Research on dairy supply chain traceability system and its pre-warning model", in Proc. of 2016 International Conference on Logistics, Informatics and Service Sciences (LISS), 2016, pp. 1-6. DOI: 10.1109/LISS.2016.7854599.

[12] M. Yu and A. Nagurney, "Competitive food supply chain networks with application to fresh produce", Eur. J. Oper. Res., vol. 224, no. 2, pp. 273-282, Jan. 2013. DOI: 10.1016/j.ejor.2012.07.033.

[13] M. M. Aung and Y. S. Chang, "Traceability in a food supply chain: Safety and quality perspectives", Food Control, vol. 39, pp. 172-184, May 2014. DOI: 10.1016/j.foodcont.2013.11.007.

[14] European Parliament and the Council, EC 178/2002 General principles and requirements of food law, establishing the European Food Safety Authority, 2002.

[15] G. C. Smith et al., "Traceability from a US perspective", Meat Sci., vol. 71 , no. 1 , pp. 174-193, Sep. 2005. DOI: 10.1016/j.meatsci.2005.04.002.

[16] A. Musa, A. Gunasekaran, and Y. Yusuf, "Supply chain product visibility: Methods, systems and impacts", Expert Syst. Appl., vol. 41, no. 1, pp. 176-194, Jan. 2014. DOI: 10.1016/j.eswa.2013.07.020.

[17] B. Jachimczyk, A. Lubowicki, R. Ogielski, M. Bonecki, and W. J. Kulesza, "The agile-based monitoring and management system for dairy supply chain - The user driven design approach", Przedsiębiorczość i Zarządzanie, vol. 18, pp. 395-412, 2017.

[18] C. Colicchia, A. Creazza, and F. Dallari, "Lean and green supply chain management through intermodal transport: Insights from the fast moving consumer goods industry", Prod. Plan. Control, vol. 28, no. 4, pp. 321-334, 2017. DOI: 10.1080/09537287.2017.1282642.

[19] R. Ogielski and A. Lubowicki, "The agile-based monitoring and management system for dairy supply chain: The user driven design approach", M.S. thesis, Blekinge Institute of Technology, Karlskrona, 2017. [Online]. Available: http://www.divaportal.org/smash/record.jsf?pid=diva2\%3A1156386\&dswid=-8650

[20] J.-P. Qian et al., "A traceability system incorporating 2D barcode and RFID technology for wheat flour mills", Comput. Electron. Agric., vol. 89, pp. 76-85, Nov. 2012. DOI: 10.1016/j.compag.2012.08.004.

[21] J. Feng, Z. Fu, Z. Wang, M. Xu, and X. Zhang, "Development and 
evaluation on a RFID-based traceability system for cattle/beef quality safety in China", Food Control, vol. 31, no. 2, pp. 314-325, Jun 2013. DOI: 10.1016/j.foodcont.2012.10.016.

[22] P. Barge, P. Gay, V. Merlino, and C. Tortia, "Item-level RadioFrequency IDentification for the traceability of food products: Application on a dairy product", J. Food Eng., vol. 125, pp. 119-130, Mar. 2014. DOI: 10.1016/j.jfoodeng.2013.10.019.

[23] L. Ramundo, M. Taisch, and S. Terzi, "State of the art of technology in the food sector value chain towards the IoT", in Proc. of 2016 IEEE 2nd International Forum on Research and Technologies for Society and Industry Leveraging a better tomorrow (RTSI), 2016, pp. 1-6. DOI: 10.1109/RTSI.2016.7740612.

[24] B. Cortés, A. Boza, D. Pérez, and L. Cuenca, "Internet of Things applications on supply chain management", World Acad. Sci. Eng. Technol., Int. J. Comput. Electr. Autom. Control Inf. Eng., vol. 9, no. 12, pp. 2493-2498, 2015.

[25] D. Ivanov, A. Dolgui, and B. Sokolov, "The impact of digital technology and Industry 4.0 on the ripple effect and supply chain risk analytics”, Int. J. Prod. Res., vol. 57, no. 3, pp. 829-846, 2019. DOI: 10.1080/00207543.2018.1488086.

[26] G. L. Geerts and D. E. O'Leary, “A supply chain of things: The EAGLET ontology for highly visible supply chains", Decis. Support Syst., vol. 63, pp. 3-22, Jul. 2014. DOI: 10.1016/j.dss.2013.09.007.

[27] P. Lou, Q. Liu, Z. Zhou, and H. Wang, "Agile supply chain management over the Internet of Things", in Proc. of 2011 International Conference on Management and Service Science, 2011, pp. 1-4. DOI: 10.1109/ICMSS.2011.5998314.

[28] A. A. Majeed and Th. D. Rupasinghe, "Internet of Things (IoT) embedded future supply chains for Industry 4.0: An assessment from an ERP-based fashion apparel and footwear industry", Int. Journal of Supply Chain Management, vol. 6, no. 1, pp. 25-40, 2017.

[29] C. N. Verdouw, J. Wolfert, A. J. M. Beulens, and A. Rialland, "Virtualization of food supply chains with the internet of things", $J$. Food Eng., vol. 176, pp. 128-136, May 2016. DOI: 10.1016/j.jfoodeng.2015.11.009.

[30] T. Pizzuti and G. Mirabelli, "FTTO: An example of Food Ontology for traceability purpose", in Proc. of 2013 IEEE 7th International Conference on Intelligent Data Acquisition and Advanced Computing Systems (IDAACS), 2013, pp. 281-286. DOI: 10.1109/IDAACS.2013.6662689.

[31] T. Pizzuti, G. Mirabelli, G. Grasso, and G. Paldino, "MESCO (MEa Supply Chain Ontology): An ontology for supporting traceability in the meat supply chain", Food Control, vol. 72, part A, pp. 123-133, Feb. 2017. DOI: 10.1016/j.foodcont.2016.07.038.

[32] Sh. Wang et al., "A conceptual modeling approach to quality management in the context of diary supply chain", in Proc. of The 2nd International Conference on Information Science and Engineering, 2010, pp. 13-16. DOI: 10.1109/ICISE.2010.5692002.

[33] J. Yue et al., "Ontology based vegetable supply chain knowledge expressing", in Proc. of 2005 First International Conference on Semantics, Knowledge and Grid, 2005, pp. 130-130. DOI: 10.1109/SKG.2005.98

[34] N. Bansal and S. K. Malik, "A framework for agriculture ontology development in semantic web", in Proc. of 2011 International Conference on Communication Systems and Network Technologies, 2011, pp. 283-286. DOI: 10.1109/CSNT.2011.68.

[35] Ch. Snae and M. Bruckner, "FOODS: A food-oriented ontologydriven system", in Proc. of 2008 2nd IEEE International Conference on Digital Ecosystems and Technologies, 2008, pp. 168-176. DOI: 10.1109/DEST.2008.4635195.

[36] L. Yue, W. Zuo, T. Peng, Y. Wang, and X. Han, "A fuzzy document clustering approach based on domain-specified ontology", Data Knowl. Eng., vol. 100, part A, pp. 148-166, Nov. 2015. DOI 10.1016/j.datak.2015.04.008.

[37] J. P. C. Verhoosel and J. Spek, "Applying ontologies in the dairy farming domain for big data analysis”, SR+SWIT@ ISWC, pp. 91$100,2016$.

[38] Quantis Switzerland, "Product environmental footprint category rules for dairy products", Lausanne, Apr. 2018. [Online]. Available: http://ec.europa.eu/environment/eussd/smgp/pdf/PEFCRDairyProducts_2018-04-25_V1.pdf

[39] International Dairy Federation, Bulletin $N^{\circ} 479 / 2015$, “A common carbon footprint approach for the dairy sector - The IDF guide to standard life cycle assessment methodology", IDF Publications Catalogue. [Online]. Available: https://store.fil-idf.org/product/acommon-carbon-footprint-approach-for-the-dairy-sector-the-idfguide-to-standard-life-cycle-assessment-methodology/
[40] S. D. K. Tomic, D. Drenjanac, S. Hoermann, and W. Auer, "Experiences with creating a precision dairy farming ontology (DFO) and a knowledge graph for the data integration platform in agriOpenLink", Journal of Agricultural Informatics, vol. 6, no. 4, pp 115-126, 2015. DOI: 10.17700/jai.2015.6.4.213.

[41] F. Mazzetto, P. Sacco, and R. Bonera, "A farm ontology for farm modelling", in Proc. of the VIII ESA Congress, Copenhagen, Denmark, 2004, pp. 249-250.

[42] C. Roussey, V. Soulignac, J. C. Champomier, V. Abt, and J. P. Chanet, "Ontologies in agriculture", in Proc. of AgEng 2010, International Conference on Agricultural Engineering, ClermontFerrand, France, 2010. [Online]. Available: https://hal.archivesouvertes.fr/hal-00523508

[43] J. M. Vicente, E. Avila-Navarro, A. Rodriguez-Martinez, M. A. de la Casa Lillo, and J. M. Sabater-Navarro, "NFC2BLE communications' bridge: From flash to continuous monitoring of biological parameters", Elektronika ir Elektrotechnika, vol. 26, no. 2, pp. 54-58, Apr. 2020. DOI: 10.5755/j01.eie.26.2.25907.

[44] G. Bylund, Dairy Processing Handbook, 2nd ed., Tetra Pak, 2015.

[45] N. Burke et al., "The dairy industry: Process, monitoring, standards, and quality", in Descriptive Food Science. IntechOpen, 2018. DOI: 10.5772/intechopen. 80398

[46] J. Ritonja, A. Gorsek, and D. Pecar, "Control of milk fermentation in batch bioreactor", Elektronika ir Elektrotechnika, vol. 26, no. 1, pp. 4-9, Feb. 2020. DOI: 10.5755/j01.eie.26.1.23377

[47] M. Ganzha et al., "Tools for ontology matching-practical considerations from INTER-IoT perspective", in Internet and Distributed Computing Systems. IDCS 2016. Lecture Notes in Computer Science, vol. 9864. Springer, Cham, 2016, pp. 296-307. DOI: 10.1007/978-3-319-45940-0_27.

[48] M. Ganzha, M. Paprzycki, W. Pawlowski, P. Szmeja, and K. Wasielewska, "Semantic technologies for the IoT - An inter-IoT perspective", in Proc. of 2016 IEEE First International Conference on Internet-of-Things Design and Implementation, 2016, pp. 271-276. DOI: 10.1109/IoTDI.2015.22.

[49] J. Angele and M. Gesmann, "Data integration using semantic technology: A use case", in Proc. of 2006 Second International Conference on Rules and Rule Markup Languages for the Semantic Web, 2006, pp. 58-66. DOI: 10.1109/RULEML.2006.9.

[50] C. Batini, M. Lenzerini, and S. B. Navathe, "A comparative analysis of methodologies for database schema integration", ACM Comput. Surv., vol. 18, no. 4, pp. 323-364, Dec. 1986. DOI $10.1145 / 27633.27634$.

[51] M. Kifer and L. Eliezer, "A framework for an efficient implementation of deductive databases", in Proc. of the Advanced Database Symposium, Tokyo, 1986.

[52] R. Ramakrishnan and J. D. Ullman, "A survey of deductive database systems”, J. Log. Program., vol. 23, no. 2, pp. 125-149, May 1995. DOI: 10.1016/0743-1066(94)00039-9.

[53] ACCUS Consortium, "ACCUS Project", artemis-ia-eu. [Online] Available: https://artemis-ia.eu/project/50-accus.html

[54] OpenIoT Consortium, "OpenIoT - Open Source cloud solution for the Internet of Things". [Online]. Available: http://www.openiot.eu/

[55] A. Kazmi, M. Serrano, and J. Soldatos, "VITAL-OS: An open source IoT operating system for smart cities", IEEE Communications Standards Magazine, vol. 2, no. 2, pp. 71-77, Jun. 2018. DOI 10.1109/MCOMSTD.2018.1700016.

[56] Fiesta IoT Consortium, "FIESTA-IOT - Federated interoperable semantic IoT testbeds and applications", FIESTA-IOT. [Online] Available: http://fiesta-iot.eu/

[57] SymbIoTe Consortium, "symbIoTe - Symbiosis of smart objects across IoT environments". [Online]. Available: https://www.symbiote-h2020.eu/

[58] World Wide Web Consortium: Resource Description Framework "RDF - Semantic web standards". [Online]. Available: https://www.w3.org/RDF/

[59] World Wide Web Consortium: Resource Description Framework, "RDF schema 1.1". [Online]. Available: https://www.w3.org/TR/rdfschema/

[60] World Wide Web Consortium, "OWL web ontology", Nov 2009 [Online]. Available: https://www.w3.org/TR/owl-ref/\#Sublanguages

[61] Stanford University, "Protege: A free, open-source ontology editor and framework for building intelligent systems". [Online]. Available: https://protege.stanford.edu/

[62] European Commission, "Common agricultural policy". [Online]. Available: https://ec.europa.eu/info/food-farming-fisheries/keypolicies/common-agricultural-policy_en 
[63] United Nations Resolution A/RES/70/1 "General Assembly, Transforming our world: The 2030 agenda for sustainable sevelopment", Oct. 2015. [Online]. Available: https://www.un.org/ga/search/view_doc.asp?symbol=A/RES/70/1\&L ang $=\mathrm{E}$
[64] European Commision, "Product environmental footprint category rules guidance", version 6.3, May 2018. [Online]. Available: http://ec.europa.eu/environment/eussd/smgp/pdf/PEFCR_guidance_v 6.3.pdf

This article is an open access article distributed under the terms and conditions of the Creative Commons Attribution 4.0 (CC BY 4.0) license (http://creativecommons.org/licenses/by/4.0/). 